\title{
Pecha Kucha with Part-Task Training Improves Airway Management in Fresh Frozen Cadavers: A Case-Control Observational Study
}

\author{
Kemal Tolga Saracoglu ${ }^{a}$ Mehmet Yilmaz $^{b}$ Ayse Zeynep Turan ${ }^{b}$ \\ Alparslan Kus ${ }^{c}$ Tuncay Colak ${ }^{d}$ Ayten Saracoglu ${ }^{\mathrm{e}}$ \\ ${ }^{a}$ Department of Anesthesiology and Intensive Care, Health Sciences University Medical School, Istanbul, Turkey; \\ ${ }^{b}$ Department of Anesthesiology and Intensive Care, Health Sciences University Medical School, Kocaeli, Turkey; \\ ${ }^{c}$ Department of Anesthesiology and Intensive Care, Kocaeli University Medical School, Kocaeli, Turkey; ${ }^{\mathrm{d}}$ Department

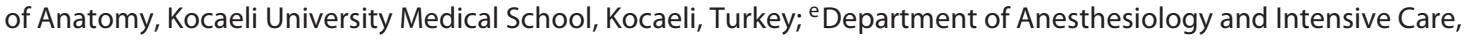 \\ Marmara University Medical School, Istanbul, Turkey
}

\section{Significance of the Study}

- Tracheal intubation remains a life-saving procedure and requires skills.

- Part-task training may provide advantages in fiberoptic-guided tracheal intubation.

- Pecha Kucha is a narrative technique which is used in medical education.

- In addition to the Pecha Kucha method, simulation-based part-task training in airway management increases the success rate.

\section{Keywords}

Airway management education - Pecha Kucha · Anesthesiology

\begin{abstract}
Objective: The objective of this study was to ascertain whether the addition of part-task training as a step in Pecha Kucha for fiberoptic tracheal intubation increases the success rate and reduces the complication rate. Subjects and Methods: The residents of the Department of Anesthesiology were initially included in an orientation program. We used the Pecha Kucha method for the presentation of teaching fiberoptic intubation skills. Afterwards the participants were trained in Laerdal ${ }^{\circledR}$ airway management and each par-
\end{abstract}

karger@karger.com www.karger.com/mpp

Karger $\stackrel{\text { ' }}{5}$

GOPEN ACCESS
C 2020 The Author(s)

Published by S. Karger AG, Basel

This is an Open Access article licensed under the Creative Commons Attribution-NonCommercial-4.0 International License (CC BY-NC) (http://www.karger.com/Services/OpenAccessLicense), applicable to the online version of the article only. Usage and distribution for commercial purposes requires written permission. ticipant performed tracheal intubation using the Aintree catheter. The participants were divided into two groups. Group $1(n=9)$ received part-task training and group 2 ( $n=$ 9) received whole-task training. The tracheal intubation performances of participants were evaluated on fresh frozen cadavers. The number of interventions, incidence of complications, success rate, and optimization maneuver requirements were recorded. Results: Eighteen residents aged between 27 and 33 years were included. All were junior residents with less than 2 years of experience. There was no significant difference in terms of duration of tracheal intubation, complication rates, and optimization maneuvers between the study groups. Six participants could not place the tracheal tube in the last section. The success rates for the part-task group during Aintree and tracheal tube placement 
were 100 and $66.7 \%$, respectively, whereas the rates were 55.6 and $44.4 \%$, respectively, in whole-task group $(p<0.05)$. Conclusion: In addition to the Pecha Kucha method in fiberoptic intubation training, simulation-based part-task training appears to increase the success rate and to reduce the complication rate on fresh frozen cadavers.

(C) 2020 The Author(s)

Published by S. Karger AG, Basel

\section{Introduction}

Tracheal intubation is a life-saving procedure that requires special skills. Fiberoptic bronchoscopy used in advanced airway management is a difficult procedure to teach in a clinical environment because this requires complex psychomotor skills and repetitive applications. New users may encounter several problems in their first attempt. One study showed that $18 \%$ of residents still needed help after 80 tracheal intubations [1]. The Difficult Airway Society has published a detailed guideline describing the stages of tracheal intubation through a supraglottic airway device (SAD) [2].

Pecha Kucha is an educational technique developed by Japanese scientists. This technique consists of 20 slides; each slide is described in $20 \mathrm{~s}$ and contains both pictures and videos. It has been shown to be useful in effective learning in clinical studies $[3,4]$.

On the other hand, the method of teaching a lecture by pieces (part-task) or as an entity (whole-task) has been in practice since the beginning of the 20th century. In part-task training, students practice on the subject components before performing the assignment. Thus, each task piece is put into the learner's limited memory and task-related confusion is reduced. Part-task training is considered advantageous as individual task components are identified; however, the superiority of methods has been discussed in various studies for years [5-7].

We hypothesized that the Pecha Kucha method and part-task training for fiberoptic tracheal intubation can increase the intubation success and decrease the complication rate. Thus, routine use of this method may contribute to patient safety.

\section{Subjects and Methods}

Following approval by the Kocaeli University Medical School Ethics Committee for the study, consent of the anesthesiology and reanimation trainees was obtained and they were included in this case-control observational study. The study was per- formed in the Anatomy Laboratories of Kocaeli University Medical School, Kocaeli, Turkey. The participants were voluntary residents from two different university hospitals and they were included in an orientation program. Fiberoptic tracheal intubation through SAD was described using the Pecha Kucha method and visuals to the participants. The lecture consisted of 20 slides and each image was presented for $20 \mathrm{~s}$ (online suppl. video; see www.karger.com/doi/1011.59/000506597). Thereafter, a video created by a trainer experienced in tracheal intubation through the SAD was displayed to the participants. After all the participants had completed the orientation, practical training was given using the Laerdal ${ }^{\circledR}$ normal head-neck airway manikin.

The participants were randomly divided into two groups (Fig. 1). Group $1(n=9)$ received part-task training and group 2 $(n=9)$ received whole-task training. Randomization was performed by using the True Random Number Generator from www. random.org. Fiberoptic intubation was described and applied at one time in the whole-task training group. Participants in this group were expected to perform laryngeal mask placement, ventilation, fiberoptic bronchoscopy, and insertion of the intubation tube through the Aintree catheter as described in the Difficult Airway Society guideline, at one time.

In the part-task group, tracheal intubation was taught in two stages at the same time as in the whole-task group. Participants were expected to learn laryngeal mask placement, ventilation, and fiberoptic visualization of the vocal cords at the first stage (T1), followed by placement of the Aintree catheter (T2). At the second stage, the laryngeal mask was removed and the tracheal tube was inserted (T3). Confirmation of adequate ventilation was accepted as successful tracheal intubation.

After all participants had completed the practice, tracheal intubation performances were evaluated on a fresh frozen cadaver. The number of attempts, complications, success rate, the duration of tracheal intubation, and the optimization maneuvers were recorded. Intubation time was recorded in three stages: T1 started with holding the laryngeal mask in hand and ended with visualization of the vocal cords. T2 started after visualization of the vocal cords, recorded as the insertion time of the Aintree catheter. T3 ended with the removal of the laryngeal mask, placement of the tracheal intubation tube, and effective ventilation of the lungs. The impact of resident seniority on tracheal intubation time was assessed as Seniority $1(n=6)$, Seniority $2(n=7)$, and Seniority 3 $(n=5)$. Seniority 1 included residents who had less than 6 months of experience, Seniority 2 residents who had between 6 months and 1 year of experience, and Seniority 3 residents who had between 1 and 2 years of experience. Participants were also asked about their time spent playing computer games (recorded as hours).

\section{Statistical Analysis}

Data obtained from the study were analyzed using IBM SPSS Statistics 24 . From numerical data, in the binary comparison of the part-task and whole-task groups, independent samples $t$ test was used for normal distribution, Mann-Whitney U test for nonnormal distribution, and $\chi^{2}$ test for analysis of discrete variables. In the triple comparison of resident seniority, one-way ANOVA and correlation test for nonnormal distribution were used. The results were evaluated with a $95 \%$ confidence interval and significance was appraised at $p<0.05$. 
Fig. 1. Flowchart of the participants.

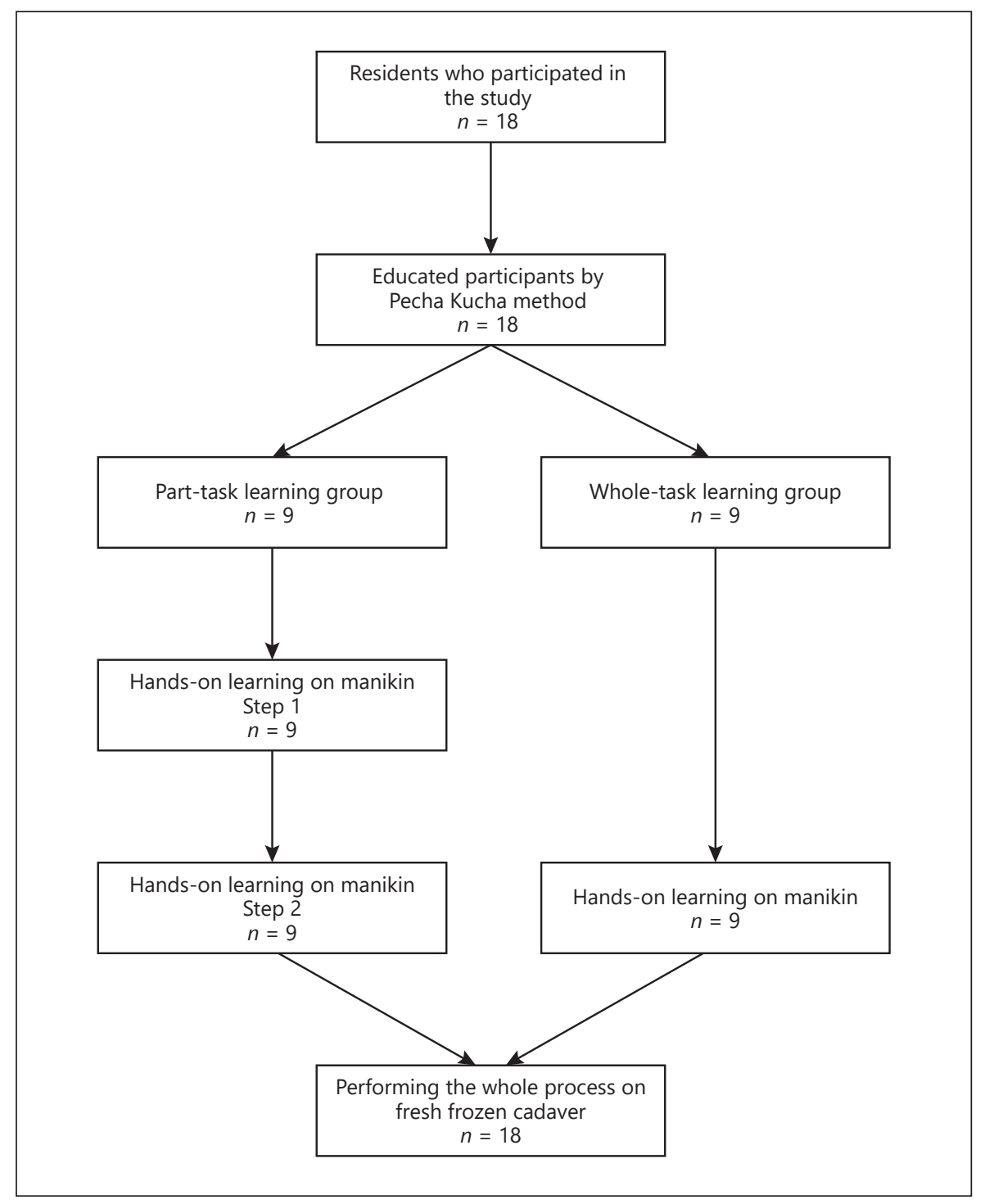

Table 1. Comparison of the demographic data of the groups

\begin{tabular}{lccl}
\hline & $\begin{array}{c}\text { Group 1 } \\
(n=9)\end{array}$ & $\begin{array}{l}\text { Group 2 } \\
(n=9)\end{array}$ & $\begin{array}{l}p \\
\text { value }\end{array}$ \\
\hline Sex & & & \\
$\quad$ Female & 4 & 4 & $1.00^{\mathrm{a}}$ \\
$\quad$ Male & 5 & 5 & \\
Age, years & $28 \pm 3.5$ & $28.0 \pm 3$ & $0.335^{\mathrm{b}}$ \\
Playing computer games, h/week & $0 \pm 10$ & $0 \pm 5$ & $0.614^{\mathrm{b}}$ \\
Attempts & $2 \pm 5$ & $3 \pm 2.5$ & $0.111^{\mathrm{b}}$ \\
Success rate, \% & $50 \pm 100$ & $0 \pm 66.5$ & $0.413^{\mathrm{b}}$ \\
\hline
\end{tabular}

Values are given as $n$ or mean \pm standard deviation. ${ }^{a} \chi^{2}$ test. ${ }^{\mathrm{b}}$ Mann-Whitney U test.

\section{Results}

This study included 18 anesthesiology and intensive care trainees, ranging in age from 27 to $33(29.06 \pm 2.05)$ years. None of the participants were excluded from the study. Eight were female (44.4\%) and 10 were male (55.6\%). There were no significant differences between the two groups in terms of complications, time spent playing computer games, or optimization maneuvers (Table 1). There was no significant age difference between the two groups. The relationship between resident seniority and tracheal intubation time was assessed. There was a positive correlation between T2 and T3 intubation time $(r=0.893, p=0.000)$, but no relationship was observed between groups regarding the time for removal of the laryngeal mask and placement of the 
Table 2. Evaluation of the relationship between resident seniority and tracheal intubation time

\begin{tabular}{lccll}
\hline & $\begin{array}{l}\text { Seniority 1 } \\
(n=6)\end{array}$ & $\begin{array}{l}\text { Seniority 2 } \\
(n=7)\end{array}$ & $\begin{array}{l}\text { Seniority } 3 \\
(n=5)\end{array}$ & $p$ value \\
\hline T1 & $24.00 \pm 15.23$ & $23.29 \pm 11.70$ & $27.20 \pm 11.41$ & $0.867^{\mathrm{a}}$ \\
T2 & $266.00 \pm 222.43$ & $406.83 \pm 157.08$ & $248.8 \pm 147.08$ & $0.287^{\mathrm{a}}$ \\
T3 & - & $56.80 \pm 31.64$ & $52.75 \pm 32.51$ & $0.755^{\mathrm{a}}$ \\
\hline
\end{tabular}

Values are given as mean \pm standard deviation. ${ }^{\text {a }}$ One-way ANOVA.

tracheal tube (Table 2). Eight participants were unable to insert the tracheal tube. All of them were trainees with less than 2 years of experience. In the part-task group, the success rates in the T2 and T3 periods were 100 and $66.7 \%$, respectively. In the whole-task group, the success rate in the $\mathrm{T} 2$ period was $55.6 \%$. The success rate in the T3 period was $44.4 \%(p<0.05)$ (Table 3$)$. The Pearson correlation analysis between success rates in different periods of tracheal intubation and the seniority of trainees are shown in Figure 2 . No correlation was found between resident seniority and intubation times $(p>0.05)$. There was no statistically significant difference between the success rates of tracheal intubation and resident seniority.

\section{Discussion}

In this observational study, anesthesiology and intensive care trainees were taught fiberoptic tracheal intubation by using the proven Pecha Kucha method. The part-task method was used as an additional education technique; the success rate increased by using the whole-task method.

Thoughts can be better expressed by visual elements than words. In this way, it is possible to attract the highest level of participants' interest and create a good learning environment. Therefore, we chose the Pecha Kucha method. Pecha Kucha comes from the Japanese "pachok-cha" and is a presentation method designed to engage the attention of the audience $[8,9]$. The total presentation time does not exceed $6 \mathrm{~min}$ and $40 \mathrm{~s}$ [10]. Thus, it is possible to perform dynamic and systematic presentations in the medical field $[3,11]$. Modern airway management training should combine both the task of training technical skills and the "nontechnical issue" including effective communication [12]. The Pecha Kucha method has been used in plastic surgery training to improve communication skills [9]. In this study it was concluded that
Table 3. Success rates of the groups at each steps of tracheal intubation

\begin{tabular}{llll}
\hline & $\begin{array}{l}\text { Group 1 } \\
(n=9)\end{array}$ & $\begin{array}{l}\text { Group 2 } \\
(n=9)\end{array}$ & $p$ value \\
\hline $\begin{array}{l}\text { Insertion of the SAD and viewing the vocal cords } \\
\text { Unsuccessful }\end{array}$ & $0(0 \%)$ & $4(44.4 \%)$ & $0.082^{\mathrm{a}}$ \\
$\begin{array}{l}\text { Successful } \\
\text { Insertion of the tracheal tube }\end{array}$ & $9(100 \%)$ & $5(55.6 \%)$ & \\
$\quad \begin{array}{l}\text { Unsuccessful } \\
\text { Successful }\end{array}$ & $3(33.3 \%)$ & $5(55.6 \%)$ & $0.637^{\mathrm{a}}$ \\
\hline
\end{tabular}

Values are given as $n(\%)$. ${ }^{\text {a }} \chi^{2}$ test. SAD, supraglottic airway device.

this method provided sufficient time to express ideas. Pecha Kucha has also been reported to be useful in the training of psychology, medicine, and nursing students $[4,13]$. For this purpose 120 first-year undergraduate medical students were evaluated by involving them in Pecha Kucha talks. The Pecha Kucha method was useful for them to apply creativity $(72.5 \%)$ and to learn how to present concise information (65.8\%). Ramos-Rincón et al. [8] stated that Pecha Kucha has the potential to foster students' capacities in analysis, synthesis, and even abstraction. However, in this study we found that when the Pecha Kucha method was used in combination with parttask training, more successful results could be achieved.

In our study, all participants in the part-task group successfully completed the first two stages of tracheal intubation, i.e., placement of the SAD and visualization of the vocal cords. In the whole-task group, the total success rate was only $55 \%$. However, this was not statistically significant. We are of the opinion that this may be due to the small sample size.

Several methods for teaching fiberoptic intubation skills are available. Virtual reality simulators can provide objective assessment of clinical performance in a safe way for learners [14]. A recently developed virtual reality simulator, the ORSIM ${ }^{\circledR}$ bronchoscopy simulator (Airway Simulation Ltd., Auckland, New Zealand), aims to address the difficulties of advanced airway training by incorporating virtual patients [15]. Nilsson et al. [16] compared fiberoptic intubation with a different method by using part-task and whole-task methods. In that manikin study, they did not find a significant difference between the two groups. However, the most important difference in our study was the use of fresh frozen cadavers after the participants had practiced on manikins. The main reason was the feature of cadavers to create an environment as in our clinical practice. In our 
Fig. 2. Pearson correlation analyses of the relationship between resident seniority and tracheal intubation time.

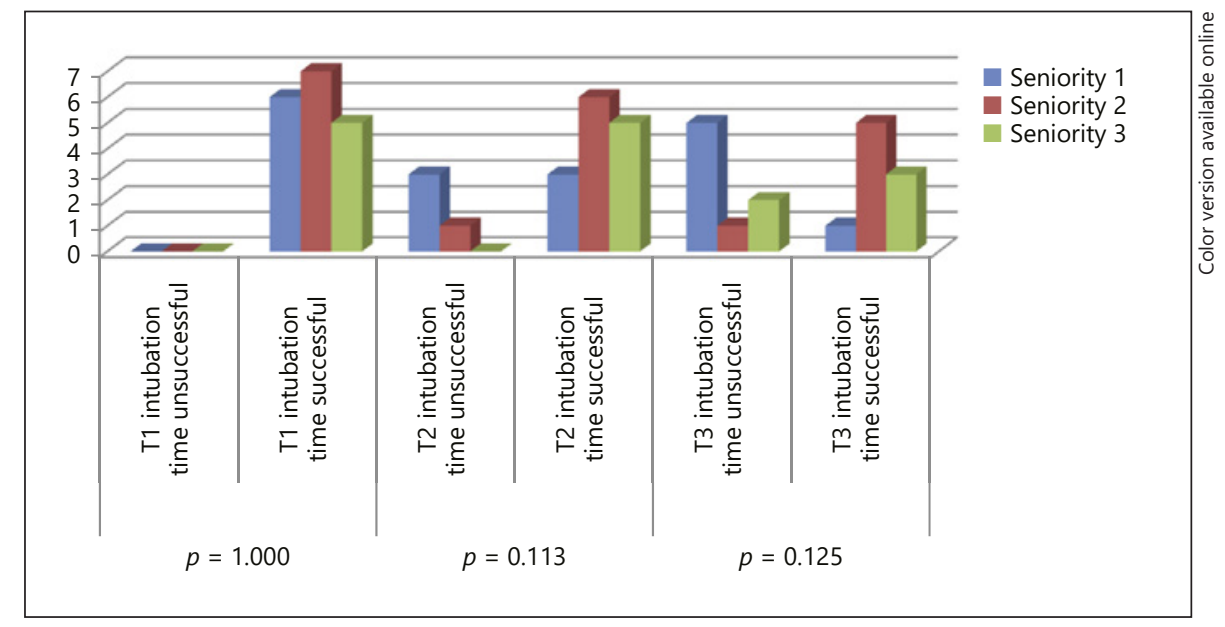

study, 8 of the participants who were allowed to practice to be confident on the manikin were unable to perform the last step of inserting the tracheal tube. This clearly shows that manikins may not always replicate the real patient. In a study comparing manikins with fresh frozen cadavers for direct laryngoscopy training, it was found that cadaverbased training was favored because the cadavers had a more realistic appearance [17]. In another study, the effectiveness of the most commonly preferred airway simulators was compared using head and neck computed tomography images of 20 trauma patients [18]. It was found that the upper airway anatomy of 4 high-fidelity patient simulators and 2 airway trainers did not resemble real patients. As a result of this, we conclude that the outcomes of our study are realistic and correlate with clinical conditions.

In previous studies the part-task technique was used to teach fiberoptic intubation, and our results support these studies $[19,20]$. Part-task training has been reported to be advantageous over whole-task training. In our study, the complication rate was not different in the two groups, but the success rate was higher in the part-task group. The most important reason for this is the faster improvement when each subject learns in divided tasks [21].

Playing computer games was reported to increase the success rate in applications requiring complex motor skills, such as laparoscopic surgery [22]. On the other hand, this issue is controversial and there are also studies reporting that playing games does not affect the skills related to clinical device use [23]. In this study, we investigated how often and how long participants played computer games. However, contrary to some previous studies, the difference was not statistically significant.

In our study, both tracheal intubation steps and residents' seniority were evaluated in three different catego- ries. There was no significant relationship between these time periods and seniority. However, the success rate for tracheal tube insertion was lowest in residents with least seniority.

\section{Limitations}

The most important limitation is that the success rate of the fiberoptic intubation training could not be evaluated in clinical practice. However, the participants received feedback from experienced trainers and had the opportunity to correct their mistakes, by this way learning various solutions. At the end of the study they had the opportunity to apply their experience when they encountered real patients in their clinical practice. As a follow-up section of our research, we decided to explore the performance of our residents in the real clinical scenario. For this purpose we asked them individually, "Did this study improve your practice in the clinical setting and would you use this technique if you encounter difficult intubation?" We received $85 \%$ positive responses.

Another limitation is the single use of bronchoscopy in the whole-task training group at the beginning of training. In the part-task group, participants had one extra chance to use. In order to prevent bias, the same training duration was given to both groups.

\section{Conclusion}

Simulation-based part-task training added to the Pecha Kucha method was shown to be successful for fiberoptic intubation training on fresh frozen cadavers. Therefore, this combined technique can be an option for trainees' education. 


\section{Statement of Ethics}

Written informed consent of the trainees was obtained following approval by the Kocaeli University Medical School Ethics Committee.

\section{References}

1 Konrad C, Schüpfer G, Wietlisbach M, Gerber $\mathrm{H}$. Learning manual skills in anesthesiology: is there a recommended number of cases for anesthetic procedures? Anesth Analg. 1998 Mar;86(3):635-9.

2 Frerk C, Mitchell VS, McNarry AF, Mendonca C, Bhagrath R, Patel A, et al.; Difficult Airway Society intubation guidelines working group. Difficult Airway Society 2015 guidelines for management of unanticipated difficult intubation in adults. Br J Anaesth. 2015 Dec;115(6):827-48.

3 Carroll AJ, Tchangalova N, Harrington EG. Flipping one-shot library instruction: using Canvas and Pecha Kucha for peer teaching. J Med Libr Assoc. 2016 Apr;104(2):125-30.

4 Abraham RR, Torke S, Gonsalves J, Narayanan SN, Kamath MG, Prakash J, et al. Modified directed self-learning sessions in physiology with prereading assignments and Pecha Kucha talks: perceptions of students. Adv Physiol Educ. 2018 Mar;42(1):26-31.

5 Chan A, Singh S, Dubrowski A, Pratt DD, Zalunardo N, Nair P, et al. Part versus whole: a randomized trial of central venous catheterization education. Adv Health Sci Educ Theory Pract. 2015 Oct;20(4):1061-71.

6 Hernández-Irizarry R, Zendejas B, Ali SM, Farley DR. Optimizing training cost-effectiveness of simulation-based laparoscopic inguinal hernia repairs. Am J Surg. 2016 Feb; 211(2):326-35.

7 Villanueva C, Xiong J, Rajput S. Simulationbased surgical education in cardiothoracic training. ANZ J Surg. doi: 10.1111/ans.15593 [Epub ahead of print].

\section{Disclosure Statement}

The authors have no conflict of interest to declare.
8 Ramos-Rincón JM, Sempere-Selva TS, Romero-Nieto M, Peris-García J, Martínez-de la Torre G, Harris M, et al. Pecha Kucha presentations by medical students in Spain. Int J Med Educ. 2018 Sep;9:244-5.

9 Ramos-Gallardo G, Mecott-Rivera GÁ, Limon-Cervantes R, García-Pérez M, Rodríguez-Olivares E. How to improve speaking skills in plastic surgery training? Survey in residents participants in Pecha Kucha Contest. World J Plast Surg. 2018 May;7(2):16670.

10 Byrne MM. Presentation innovations: using Pecha Kucha in nursing education. Teach Learn Nurs. 2016;11(1):20-2.

11 Metcalf A, Layton MV, Goslin TL. Three ways to improve student presentations. TESOL J. 2016;7(2):421-8.

12 Sorbello M, Afshari A, De Hert S. Device or target? A paradigm shift in airway management: implications for guidelines, clinical practice and teaching. Eur J Anaesthesiol. 2018 Nov;35(11):811-4.

13 Masters JC, Holland BE. Rescuing the student presentation with Pecha Kucha. J Nurs Educ. 2012 Sep;51(9):536.

14 Wong DT, Mehta A, Singh KP, Leong SM, Ooi A, Niazi A, et al. The effect of virtual reality bronchoscopy simulator training on performance of bronchoscopic-guided intubation in patients: A randomised controlled trial. Eur J Anaesthesiol. 2019 Mar;36(3):22733.

15 Baker PA, Weller JM, Baker MJ, Hounsell GL, Scott J, Gardiner PJ, et al. Evaluating the ORSIM $^{\circledR}$ simulator for assessment of anaesthetists' skills in flexible bronchoscopy: aspects of validity and reliability. Br J Anaesth. 2016 Sep; 117(Suppl 1):i87-91.
16 Nilsson PM, Russell L, Ringsted C, Hertz P, Konge L. Simulation-based training in flexible fibreoptic intubation: A randomised study. Eur J Anaesthesiol. 2015 Sep;32(9):609-14.

17 Yang JH, Kim YM, Chung HS, Cho J, Lee HM, Kang GH, et al. Comparison of four manikins and fresh frozen cadaver models for direct laryngoscopic orotracheal intubation training. Emerg Med J. 2010 Jan;27(1):13-6.

18 Schebesta K, Hüpfl M, Rössler B, Ringl H, Müller MP, Kimberger O. Degrees of reality: airway anatomy of high-fidelity human patient simulators and airway trainers. Anesthesiology. 2012 Jun;116(6):1204-9.

19 Boet S, Bould MD, Diemunsch PA. Looking beyond model fidelity. Anesthesiology. 2009 Jun;110(6):1428-9.

20 Chandra DB, Savoldelli GL, Joo HS, Weiss ID, Naik VN. Fiberoptic oral intubation: the effect of model fidelity on training for transfer to patient care. Anesthesiology. 2008 Dec; 109(6):1007-13.

21 Johnson KB, Syroid ND, Drews FA, Ogden LL, Strayer DL, Pace NL, et al. Part Task and variable priority training in first-year anesthesia resident education: a combined didactic and simulation-based approach to improve management of adverse airway and respiratory events. Anesthesiology. 2008 May; 108(5):831-40.

22 Jalink MB, Goris J, Heineman E, Pierie JP, ten Cate Hoedemaker HO. The effects of video games on laparoscopic simulator skills. Am J Surg. 2014 Jul;208(1):151-6.

23 Halvorsen FH, Cvancarova M, Fosse E, Mjåland O. Effect of computer game playing on baseline laparoscopic simulator skills. Surg Laparosc Endosc Percutan Tech. 2013 Aug; 23(4):394-9. 